\title{
Humoral and cell-mediated immune responses to H5N1 plant- made virus-like particle vaccine are differentially impacted by alum and GLA-SE adjuvants in a Phase 2 clinical trial
}

\author{
Stéphane Pillet ${ }^{1,2}$, Éric Aubin ${ }^{1}$, Sonia Trépanier ${ }^{1}$, Jean-François Poulin ${ }^{3}$, Bader Yassine-Diab ${ }^{3}$, Jan ter Meulen ${ }^{4,5}$, Brian J. Ward ${ }^{2}$ and \\ Nathalie Landry ${ }^{1}$
}

The hemagglutinination inhibition $(\mathrm{HI})$ response remains the gold standard used for the licensure of influenza vaccines. However, cell-mediated immunity (CMI) deserves more attention, especially when evaluating H5N1 influenza vaccines that tend to induce poor $\mathrm{HI}$ response. In this study, we measured the humoral response (HI) and CMI (flow cytometry) during a Phase II dose-ranging clinical trial (NCT01991561). Subjects received two intramuscular doses, 21 days apart, of plant-derived virus-like particles (VLP) presenting the $\mathrm{A} /$ Indonesia/05/2005 H5N1 influenza hemagglutinin protein (H5) at the surface of the VLP (H5VLP). The vaccine was co-administrated with Alhydrogel or with a glucopyranosyl lipid adjuvant-stable emulsion (GLA-SE). We demonstrated that low doses (3.75 or $7.5 \mu \mathrm{g} \mathrm{H5VLP)} \mathrm{of} \mathrm{GLA-SE-adjuvanted} \mathrm{vaccines} \mathrm{induced} \mathrm{HI} \mathrm{responses} \mathrm{that} \mathrm{met} \mathrm{criteria} \mathrm{for} \mathrm{licensure} \mathrm{at} \mathrm{both} \mathrm{antigen}$ doses tested. Alhydrogel adjuvanted vaccines induced readily detectable $\mathrm{HI}$ response that however failed to meet licensure criteria at any of three doses $(10,15$ and $20 \mu \mathrm{g})$ tested. The H5VLP also induced a sustained (up to 6 months) polyfunctional and crossreactive $\mathrm{HA}$-specific $\mathrm{CD}^{+} \mathrm{T}$ cell response in all vaccinated groups. Interestingly, the frequency of central memory Th1-primed precursor cells before the boost significantly correlated with HI titers 21 days after the boost. The ability of the low dose GLA-SEadjuvanted H5VLP to elicit both humoral response and a sustained cross-reactive CMI in healthy adults is very attractive and could result in significant dose-sparing in a pandemic situation.

npj Vaccines (2018)3:3 ; doi:10.1038/s41541-017-0043-3

\section{INTRODUCTION}

Since the first recorded direct bird-to-human transmission of highly pathogenic avian influenza H5N1 in Hong Kong in 1997, these viruses have spread to several countries causing widespread death and illness in domestic and migratory birds as well as human infections and fatalities. Since 2003, the World Health Organization (WHO) ${ }^{1}$ has recorded 860 confirmed $\mathrm{H} 5 \mathrm{~N} 1$ cases with 454 fatalities (i.e., $52.8 \%$ case-fatality rate, as of October 2017). Emergence of drug-resistant strains of avian H5N1 viruses strengthened the fact that vaccination remains the most effective public health intervention strategy and must be supported by enhanced surveillance networks. However, latest outbreaks highlighted the overall needs to improve the manufacturing capacity of influenza vaccine worldwide. ${ }^{2}$ Additionally, manufacturing capacity of vaccines against H5N1 viruses is limited due to the lethality of those highly pathogenic viruses to the embryonated eggs, which remains the most common producing system for influenza vaccine. ${ }^{3}$ Virus-like particle (VLP) expressing influenza antigenic protein can overcome most of the current pitfalls associated with traditional egg-based technologies, especially the plant-made VLP. ${ }^{4-8}$ Immunogenicity of influenza vaccines was historically evaluated regarding the antibody response, which remains the essential criteria for licensure. However, cell-mediated immunity (CMI) has been demonstrated to contribute significantly to the protection against influenza infection while playing a pivotal role in cross-protection and long-lasting immune response. ${ }^{9-13}$ We have previously demonstrated that plant-made monovalent VLP vaccines presenting influenza hemagglutinin proteins $\mathrm{H} 1$ or $\mathrm{H} 5$ induced the presence of long-term crossreactive memory $\mathrm{CD}^{+}{ }^{+} \mathrm{T}$ cells 6 months after immunization in healthy adults. ${ }^{14}$ Here we reported the short and long-term antibody responses and the CMI induced by two doses of a plantmade H5 VLP vaccine (H5VLP) adjuvanted with Alum-based (Alhydrogel ${ }^{\circ}$, Brenntag, QC) or with the synthetic toll-like receptor 4 (TLR4) agonist glucopyranosyl lipid adjuvant (GLA) formulated in a stable emulsion (GLA-SE ${ }^{\oplus}$, Immune Design Corp, WA) given 21 days apart to healthy adults during a Phase II clinical trial.

\section{RESULTS}

Three hundred-ninety subjects were randomized and $97.9 \%$ of subjects completed the study through day 42 (D42) and $80 \%$ through day 228 (D228) (Fig. 1). Over 75\% of the subjects were Caucasian, the remaining subjects were Asian or Black or African American (Suppl. Table 1). Gender was well distributed between groups with a slightly higher proportion of woman who received $7.5 \mu \mathrm{g}$ of H5VLP combined with glucopyranosyl lipid adjuvantstable emulsion (GLA-SE; 7.5 $\mu \mathrm{g}$ H5VLP + GLA group). The mean age and body mass index (BMI) were similar between groups.

\footnotetext{
${ }^{1}$ Medicago Inc., Québec G1V 3V9 QC, Canada; ${ }^{2}$ Research Institute of the McGill University Health Centre, Montreal H4A 3J1 QC, Canada; ${ }^{3}$ Caprion Biosciences, Montreal H2X 3Y7 QC, Canada; ${ }^{4}$ Immune Design, Seattle, WA 98102, USA and ${ }^{5}$ Immune Design, San Francisco, CA 94080-7006, USA

Correspondence: Nathalie Landry (Landryn@medicago.com)
}

Received: 2 June 2017 Revised: 11 December 2017 Accepted: 15 December 2017

Published online: 23 January 2018 


\begin{tabular}{|c|c|c|c|}
\hline 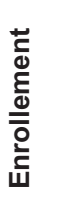 & $\begin{array}{c}\begin{array}{c}\text { Screening } \\
(n=557)\end{array} \\
\boldsymbol{v} \\
\begin{array}{c}\text { Randomized } \\
(n=390)\end{array}\end{array}$ & $\begin{array}{r}\text { Excluded } \\
(n=167)\end{array}$ & \\
\hline & $\begin{array}{l}\text { Placebo } \\
(n=65)\end{array}$ & $\begin{array}{c}10 \mu \mathrm{g} \text { VLP+alum } \\
(n=65)\end{array}$ & $\begin{array}{c}15 \mu \mathrm{g} \text { VLP+alum } \\
(n=65)\end{array}$ \\
\hline 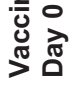 & 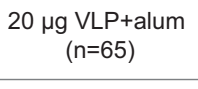 & $\begin{array}{c}3.75 \mu \mathrm{g} \mathrm{VLP+GLA-SE} \\
(n=65)\end{array}$ & $\begin{array}{c}7.5 \mu \mathrm{g} \text { VLP+GLA-SE } \\
(n=65)\end{array}$ \\
\hline & $\begin{array}{l}\text { Placebo } \\
(n=64)\end{array}$ & $\begin{array}{c}10 \mu \mathrm{g} \text { VLP+alum } \\
(\mathrm{n}=64)\end{array}$ & $\begin{array}{c}15 \mu \mathrm{g} \text { VLP+alum } \\
(n=63)\end{array}$ \\
\hline तั & $\begin{array}{c}20 \mu \mathrm{g} \text { VLP+alum } \\
(n=63)\end{array}$ & $\begin{array}{c}3.75 \mu \mathrm{g} \text { VLP+GLA-SE } \\
(\mathrm{n}=65)\end{array}$ & $\begin{array}{c}7.5 \mu \mathrm{g} \text { VLP+GLA-SE } \\
(n=63)\end{array}$ \\
\hline \multirow{2}{*}{$\begin{array}{l}\stackrel{\infty}{N} \\
\text { ন্ }\end{array}$} & $\begin{array}{l}\text { Placebo } \\
(n=62)\end{array}$ & $\begin{array}{c}10 \mu \mathrm{g} \text { VLP+alum } \\
(n=58)\end{array}$ & $\begin{array}{c}15 \mu \mathrm{g} \text { VLP+alum } \\
(n=61)\end{array}$ \\
\hline & $\begin{array}{c}20 \mu \mathrm{g} \text { VLP+alum } \\
\qquad(n=63)\end{array}$ & $\begin{array}{c}3.75 \mu \mathrm{g} \text { VLP+GLA-SE } \\
(\mathrm{n}=60)\end{array}$ & $\begin{array}{c}7.5 \mu \mathrm{g} \text { VLP+GLA-SE } \\
(n=62)\end{array}$ \\
\hline
\end{tabular}

Fig. 1 Subject disposition from screening to day 228 visit

Twenty-five percent of subjects reported to have received an influenza vaccination in the previous year (Suppl. Table 1).

Safety

The H5VLP influenza was generally well tolerated in all tested conditions after the $1 \mathrm{st}$ and the 2 nd dose. Statistical comparisons for solicited symptoms showed overall significantly higher incidences in H5VLP recipient (Suppl. Figure 1). The safety profiles of alum-adjuvanted and GLA-adjuvanted groups were similar with the exception of swelling and muscle ache after the first dose. However, the majority of solicited symptoms reported in this study were mild or moderate or $\leq$ Grade 2 intensity for all dosage regimens (data not shown).

\section{Antibody response}

The hemagglutination inhibition $(\mathrm{HI})$ titers antibody response showed that all the H5VLP + GLA groups met the European Medicines Agency's Committee for Medical Products for Human Use (CHMP) criteria after two doses; a $87.3-93.4 \%$ of seroprotection rate (SPR), a $70.5-71.4 \%$ of seroconversion rate (SCR) and a 7.8-8.3 of geometric mean fold rise (GMFR) ranges were obtained in these conditions in which lower bound of the 2-sided $95 \% \mathrm{Cl}$ did not fall below the limit of $\geq 70 \%$ for SPR, $\geq 40 \%$ for SCR and $\geq 2.5$ for GMFR (Table 1). The H5VLP + alum groups did not meet all the CHMP criteria, although the 15 and $20 \mu \mathrm{g}$ doses of vaccine reached the limit for the SCR (40.0-42.4\%) and GMFR (3.2-3.8) whereas SPR were just below 70\% (66.7-67.8\%). In addition, the $7.5 \mu \mathrm{g}$ dose of H5VLP + GLA showed a remarkable sustained $\mathrm{HI}$ titers response in which all CHMP criteria were maintained 228 days after vaccination with $75.0 \%$ (62.1-85.3\%), $43.3 \%(30.6-56.8 \%)$ and 4.2 (3.3-5.4\%) fold increase of GMT level for SPR, SCR and GMFR, respectively. Overall, the H5VLP + GLA vaccine achieved all requested $\mathrm{Hl}$-based correlates of protection with a dose as low as $3.75 \mu \mathrm{g}$ vaccine and allowed to maintain a high antibody response for 6 months following vaccination.
$T$ cell response

The $T$ cell response was assessed in ten subjects/group at day 0 (D0), day 21 (D21), D42 and D228.

The adjuvanted HSVLP induced a significant polyfunctional and sustained $C D 4^{+} T$ cell homologous response. The frequency of H5specific $\mathrm{CD}^{+} \mathrm{T}$ cells secreting one or more of the cytokines interleukine-2 (IL-2), interferon- $\gamma$ (IFN- $\gamma$ ) and tumor necrosis factora (TNF-a) significantly increased 21 days after the boost (D42) and was significantly higher than Placebo for all vaccine regimens with the exception of $7.5 \mu \mathrm{g} \mathrm{H} 5 \mathrm{VLP}+\mathrm{GLA}$ (Fig. 2a). We further detailed the impact of vaccination on all the functional signatures defined by the expression of these 3 cytokines on D42 (Fig. 2b). The frequencies of $\mathrm{IL}-2^{+} / \mathrm{IFN}-\gamma^{+}\left(\mathrm{TNF}-\mathrm{a}^{-}\right) \mathrm{CD}^{+} \mathrm{T}$ cells were extremely low $(<0.001 \%)$ and no differences were observed between vaccinated groups and Placebo in the rates of $\mathrm{H} 5$-specific single positive (SP) IFN- $\gamma^{+}\left(\mathrm{IL}^{-} 2^{-} / \mathrm{TNF}-\mathrm{a}^{-}\right)$nor $\mathrm{IL}^{-} 2^{+}\left(\mathrm{IFN}-\gamma^{-} / \mathrm{TNF}-\mathrm{a}^{-}\right) \mathrm{CD}^{+}$ $\mathrm{T}$ cells after ex-vivo stimulation at D42 (data not shown). In contrast, the frequencies of $\mathrm{H} 5$-specific polyfunctional triple positive IL-2 $2^{+} / \mathrm{IFN}-\gamma^{+} / \mathrm{TNF}-\mathrm{a}^{+}$(TP), double positive IL- $2^{+} / \mathrm{TNF}-$ $\mathrm{a}^{+}\left(\mathrm{IFN}-\gamma^{-}\right)$Th1 primed precursor cells (Thpp) and TNF-a ${ }^{+} / \mathrm{IFN}-$ $\mathrm{Y}^{+}\left(\mathrm{IL}-2^{-}\right) \mathrm{CD}^{+} \mathrm{T}$ cells significantly increased between D0 and D42 in H5VLP-vaccinated groups but not in Placebo regardless of vaccine dose or the nature of the adjuvant (Table 2 ). This resulted in significantly higher TP and Thpp H5-specific CD4 ${ }^{+} \mathrm{T}$ cells in all the H5VLP-vaccinated groups as compared to Placebo at D42, with the exception of the TP CD4 ${ }^{+}$T cells in the $20 \mu \mathrm{g} \mathrm{H} 5 \mathrm{VLP}+$ alum narrowly failing to reach statistical significance (Fig. $2 b$ ). The $\mathrm{H} 5$-specific TNF- $\mathrm{a}^{+} / \mathrm{IFN}^{-} \mathrm{\gamma}^{+}\left(\mathrm{IL}-2^{-}\right) \mathrm{CD}^{+} \mathrm{T}$ cells were also significantly higher than Placebo in the $15 \mu \mathrm{g} \mathrm{H} 5 \mathrm{VLP}+$ alum and $3.75 \mu \mathrm{g}$ H5VLP + GLA groups. SP TNF- $\mathrm{a}^{+}$also significantly increased between D0 and D42 in H5VLP-vaccinated groups with the exception of subjects who received $20 \mu \mathrm{g} \mathrm{H} 5 \mathrm{VLP}+$ alum (Table 2) and the percentage of SP TNF- $\mathrm{a}^{+} \mathrm{CD} 4^{+} \mathrm{T}$ cells were significantly higher than Placebo in the $10 \mu \mathrm{g} \mathrm{H} 5 \mathrm{VLP}$ + alum and the $2 \mathrm{GLA}-$ adjuvanted groups at D42 (Fig. 2b). Six months after the vaccination, H5VLP-vaccinated groups still exhibited significantly higher proportion of polyfunctional $\mathrm{H} 5$-specific $\mathrm{CD}^{+} / \mathrm{CD} 45 \mathrm{RA}^{-} /$ $\mathrm{CD}_{2} 7^{+}\left(\mathrm{CD}^{+}\right.$central memory, $\left.\mathrm{CM}\right)$ and $\mathrm{CD} 4^{+} / \mathrm{CD}^{+} 5 \mathrm{RA}^{-} / \mathrm{CD} 27^{-}$ 


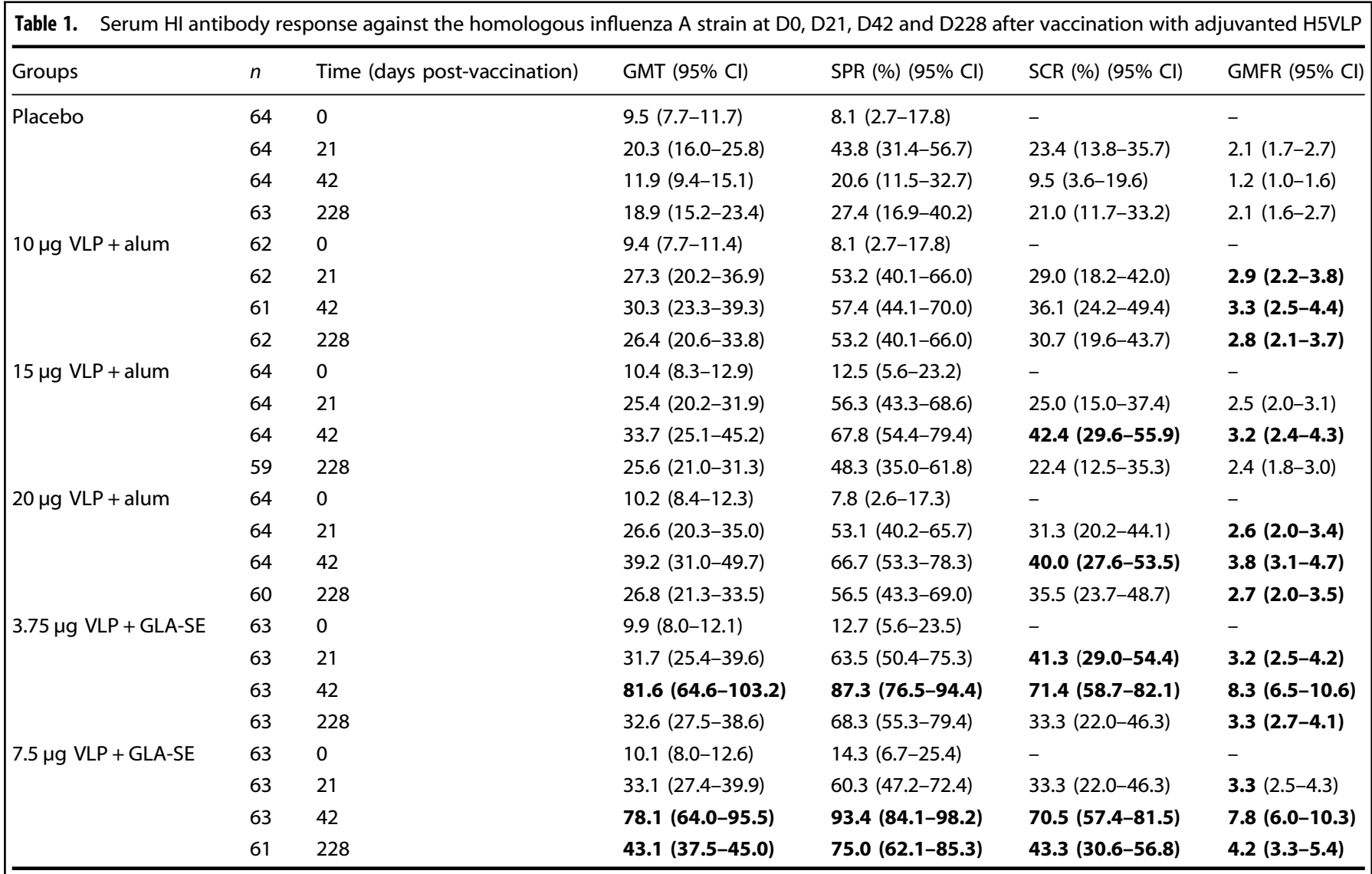

Geometric mean titer (GMT), percent of seroprotection rate (SPR), percent of seroconversion rate (SCR) and geometric mean fold increase ratio (GMFR) were reported. The GMT $\geq 40$ and values meeting the CHMP criteria for SPR ( $70 \%$ of subjects with titers $\geq 1: 32$ ), SCR (40\% of subjects with 4 -fold increase of titers with $\geq 1: 32$ value) and GMFR (2.5-fold increase of GMT from Day 0 ) are reported in bold

(CD4 ${ }^{+}$effector memory, EM) T cells compared to the Placebo (Fig. 2c, d). Notably, H5-specific Thpp CD4 ${ }^{+}$CM T cells remained significantly higher in H5VLP-vaccinated groups than Placebo with the exception of subjects who received the highest dose of alum-adjuvanted vaccine (Fig. 2c, upper panels). The higher frequencies of $\mathrm{TNF}-\mathrm{a}^{+} / \mathrm{IFN}-\gamma^{+}\left(\mathrm{IL}-2^{-}\right)$and SP TNF- ${ }^{+} \mathrm{CD}^{+} \mathrm{CM}$ $T$ cells remained significantly greater than Placebo after 6 months in vaccinated subjects in the $15-\mu \mathrm{g} \mathrm{H} 5 \mathrm{VLP}+$ alum and the $3.75 \mu \mathrm{g} \mathrm{H} 5 \mathrm{VLP}+\mathrm{GLA}$ groups, respectively. The vaccination with H5VLP also promoted H5-specific polyfunctional CD4 ${ }^{+}$ EM T cells response particularly in alum-adjuvanted groups. Although relatively high, the frequencies of $\mathrm{H} 5$-specific $\mathrm{CD} 4^{+} \mathrm{EM}$ $T$ cells in vaccinated groups were not significantly different from Placebo (likely due to the small number of subjects) with the exception of Thpp CD4 ${ }^{+}$EM T cells in the $10 \mu \mathrm{g} \mathrm{H} 5 \mathrm{VLP}+$ alum group (Fig. 2d). Overall, alum appeared to promote higher $\mathrm{H} 5$ specific long-term $\mathrm{CD}^{+} \mathrm{EM}$ T cells than GLA-SE (Fig. 2d). Perforin, granzyme B and CD107a were added as markers for $\mathrm{CD}^{+}$cytotoxicity in addition to the expression of the abovementioned cytokines. However, we did not observe significant changes in the frequencies of $\mathrm{CD}^{+} \mathrm{T}$ cells expressing functional markers (data not shown).

Pre-boost Thpp frequency significantly correlated with serologic response 21 days after the boost (D42). Although relatively low, the frequency of $\mathrm{H} 5$-specific $\mathrm{CM}$ Thpp $\mathrm{CD}^{+}{ }^{+} \mathrm{T}$ cells at D21 significantly $(P \leq 0.01)$ correlated with $\mathrm{HI}$ titers at D42 in vaccinated groups regardless of the vaccine regimen (Fig. 3 ).
The adjuvanted H5VLP induced a significant polyfunctional and sustained $C D 4^{+} T$ cell heterologous response. Influenza hemagglutinin protein $\mathrm{H} 2$-specific TP $\mathrm{CD}^{+}{ }^{+} \mathrm{T}$ cells significantly increased between D0 and D42 in H5VLP-vaccinated groups but not in Placebo (Table 2). The Thpp and TNF- $\mathrm{a}^{+} / \mathrm{IFN}-\gamma^{+}\left(\mathrm{IL}-2^{-}\right) \mathrm{CD} 4^{+}$T cells also significantly increased in all vaccinated groups with the exception of the $7.5 \mu \mathrm{g} \mathrm{H} 5 \mathrm{VLP}+\mathrm{GLA}$ (Table 2). All doses of the $\mathrm{H} 5 \mathrm{VLP}$ vaccine induced higher proportions of cross-reactive $\mathrm{H2}$ specific TP, IFN- $\gamma^{+} / \mathrm{TNF}_{-} \mathrm{a}^{+}\left(\mathrm{IL}-2^{-}\right)$and Thpp $\mathrm{CD}^{+}{ }^{+} \mathrm{T}$ cells as compared to Placebo 21 days after the boost with the exception of TP and IFN- $\gamma^{+} / \mathrm{TNF}-\mathrm{a}^{+}\left(\mathrm{IL}-2^{-}\right)$in the $7.5 \mu \mathrm{g} \mathrm{H} 5 \mathrm{VLP}+\mathrm{GLA}$ group (Fig. 4a, upper panel). Interestingly, this heterologous response occurred at the same order of magnitude as the H5-specific response. A similar cross-reactive response was observed for $\mathrm{H} 1$ although statistical significance was not reached for the Thpp $\mathrm{CD}^{+} \mathrm{T}$ cells (Fig. $4 \mathrm{a}$, lower panel). Adjuvanted H5VLP vaccine only induced limited $\mathrm{H} 7$-specific cross-reactivity at D42, eliciting significantly higher SP TNF- $\mathrm{a}^{+} \mathrm{CD}^{+} \mathrm{T}$ cells in the $7.5 \mu \mathrm{g} \mathrm{H} 5 \mathrm{VLP}$ + GLA group as compared to Placebo (data not shown). Six months after the vaccination, H5VLP-vaccinated groups still exhibited higher proportion of polyfunctional $\mathrm{H} 2$-specific $\mathrm{CD}^{+}$ CM T cells as compared to placebo (Fig. 4b). Notably, H2-specific TP CD4 ${ }^{+} \mathrm{CM}$ T cells were significantly higher in all H5VLP + alum and the $7.5 \mu \mathrm{g} \mathrm{H} 5 \mathrm{VLP}+\mathrm{GLA}$ groups. H2-specific Thpp and SP TNF$\mathrm{a}^{+} \mathrm{CD}^{+} \mathrm{CM}$ T cells were also higher than Placebo in vaccinated groups and this difference was statistically significant for the subjects who received two doses of $10 \mu \mathrm{g} \mathrm{H} 5 \mathrm{VLP}+$ alum or 3.75 $\mu \mathrm{g}$ H5VLP + GLA, respectively (Fig. 4b). 
a

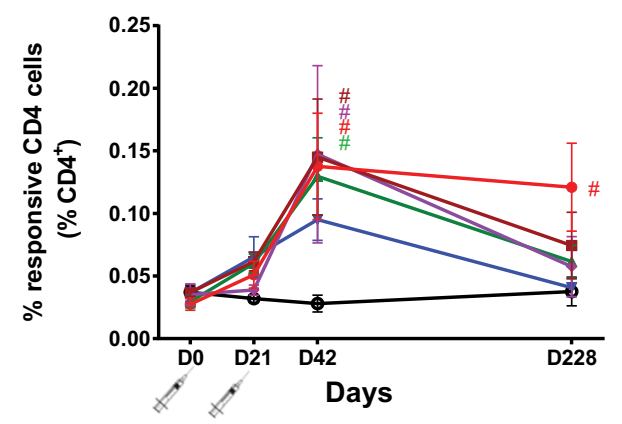

- Placebo

* $7.5 \mu \mathrm{g}$ H5VLP+GLA

$=3.75 \mu \mathrm{g} \mathrm{H} 5 \mathrm{VLP}+\mathrm{GLA}$

- $20 \mu \mathrm{g}$ H5VLP+alum

- $15 \mu \mathrm{g} \mathrm{H}$ HVLP+alum

* $10 \mu \mathrm{g}$ H5VLP+alum

b

D42

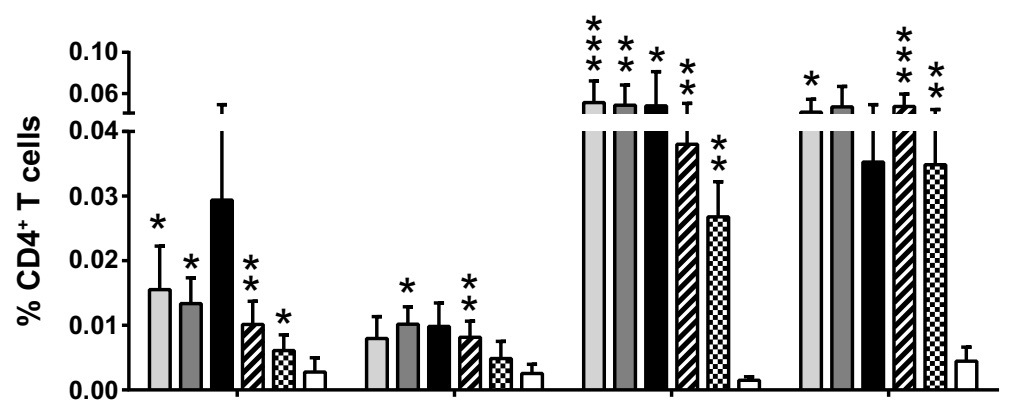

C $\quad$ 228

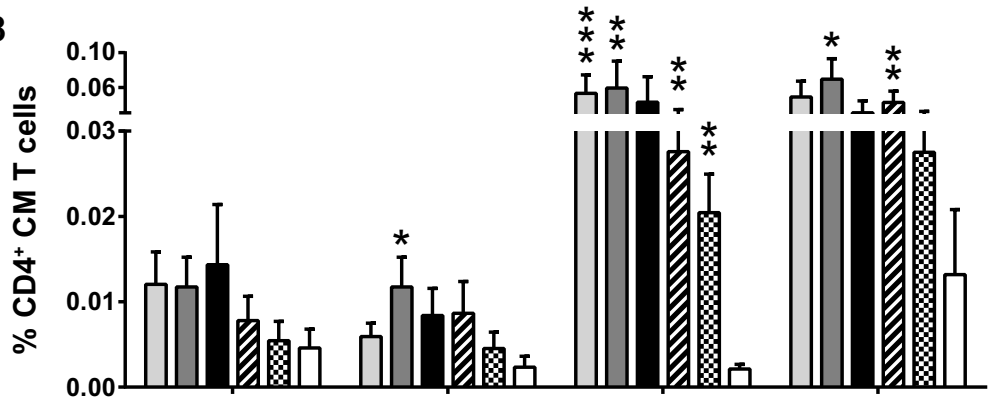

$\square 10 \mu \mathrm{g} \mathrm{H} 5 \mathrm{VLP}$

talum

$15 \mu \mathrm{g} \mathrm{H} 5 \mathrm{VLP}$

talum

$20 \mu \mathrm{g} \mathrm{H} 5 \mathrm{VLP}$

talum

$\mathbb{Z}_{\text {+GLA }}^{3.75 \mu \mathrm{H} \text { H5VP }}$

$\boldsymbol{B}_{+\mathrm{GLA}}^{7.5 \mu \mathrm{H} \text { HVLP }}$

Placebo

d

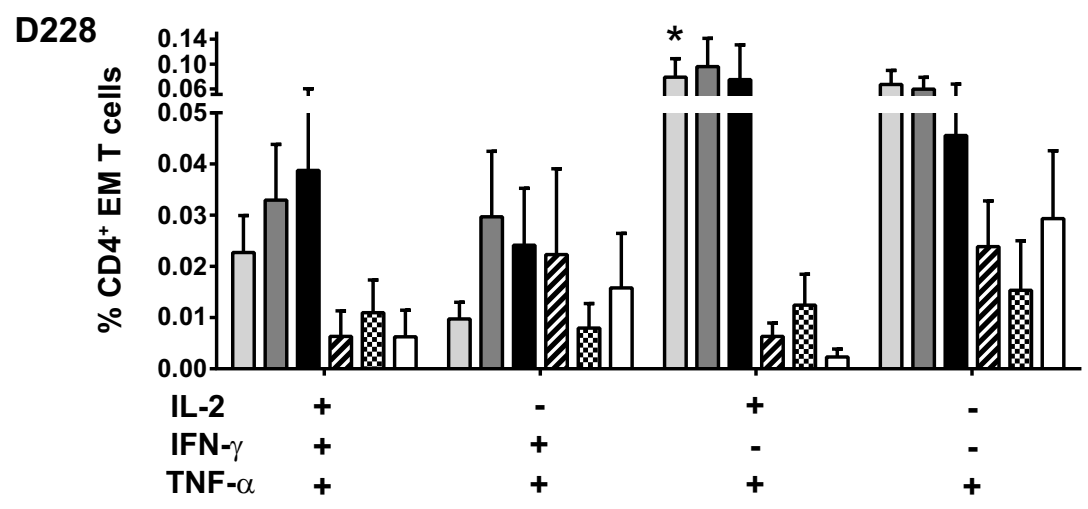

Fig. $2 \mathrm{CD}^{+}$homologous response to H5. The total percentages (mean \pm s.e.m) of $\mathrm{H} 5$-specific $\mathrm{CD} 4^{+} \mathrm{T}$ cells secreting one or more of the cytokines IL-2, IFN- $\gamma$ and TNF- $\alpha$ following ex vivo stimulation with H5 peptide pool before vaccination (D0) and on days 21 (D21), 42 (D42) and 228 (D228) were represented for the five vaccine regimens and Placebo (a). The color-matched \# indicate statistically significant differences $(P \leq 0.05$, two-way ANOVA followed by a Dunnet multiple comparison post hoc analysis, GraphPad, La Jolla, CA) with both D0 and Placebo (a). Effects of vaccination on the different functional signatures as defined by the expression of IL-2/IFN- $\gamma / \mathrm{TNF}-\alpha$ in CD4 ${ }^{+}$T cell ex vivo stimulated with $\mathrm{H} 5$ peptide pool were also assessed. The percentages (mean \pm s.e.m) of the significantly impacted CD4 ${ }^{+} \mathrm{T}_{\text {cell }}$ functional signatures (detailed at the bottom of the figure) 42 days after prime (b), CD4 ${ }^{+}$central memory T cell signatures (CM, c) and CD4 ${ }^{+}$effector memory T cell signatures $(E M, \mathbf{d}) 228$ days after prime were represented for the five vaccine regimens and Placebo. Asterisks indicate significant differences $\left({ }^{*} P \leq 0.05\right)$, ${ }^{* *} P \leq 0.01$ or $\left.{ }^{* * *} P<0.001\right)$ from Placebo for each individual functional signature (Kruskal-Wallis test, followed by Dunn's multiple comparisons test, GraphPad, La Jolla, CA) 


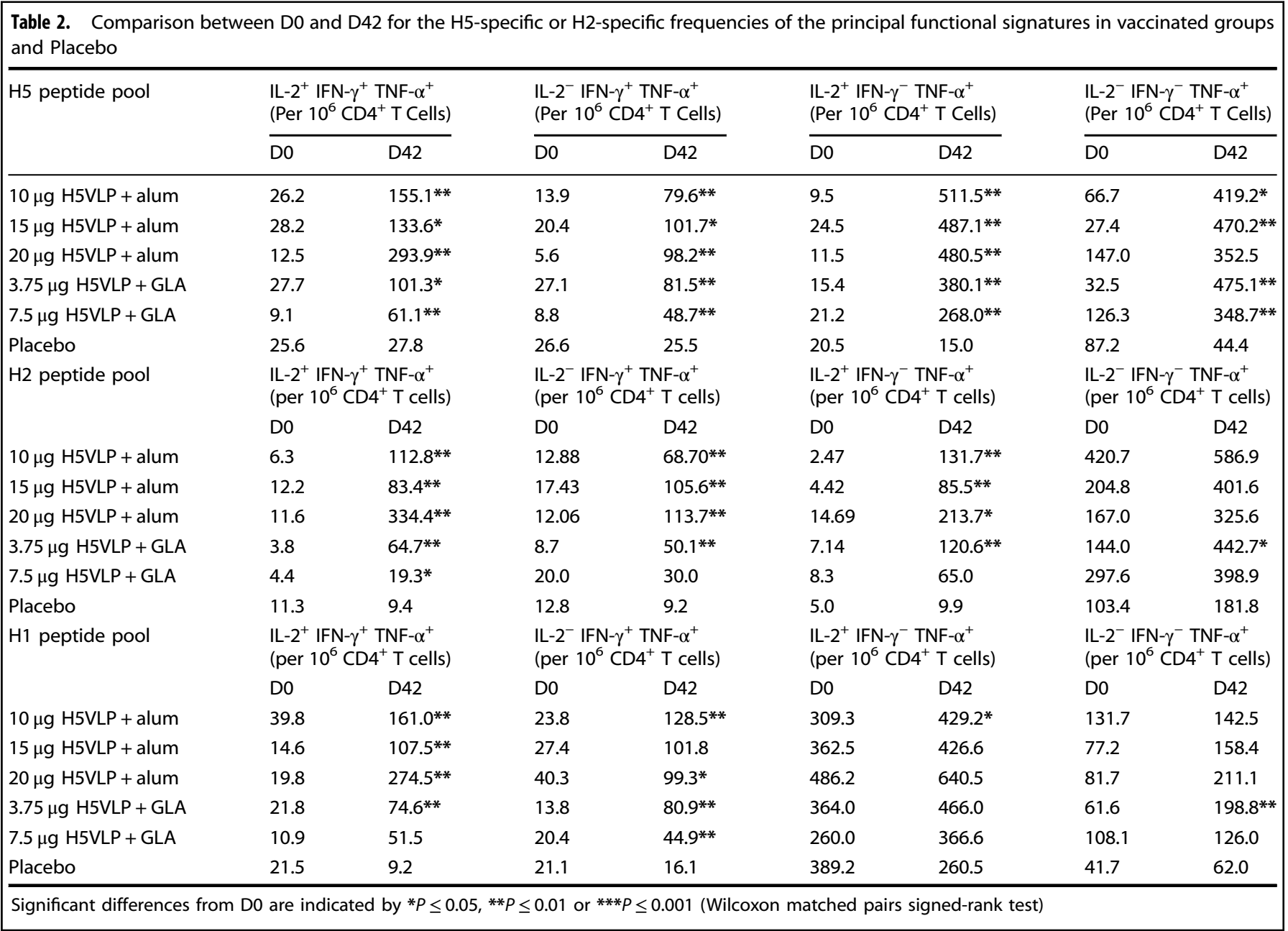

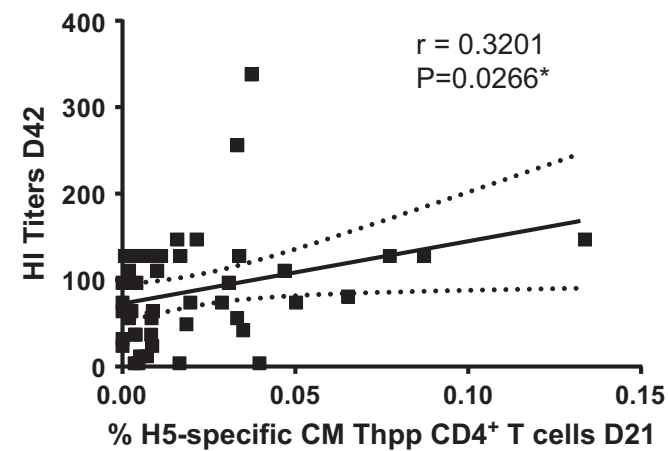

Fig. 3 Correlation between the percent of $\mathrm{H} 5$-specific central memory (CM) CD45RA ${ }^{-}$CD27 $7^{+}$Thpp (IL-2 ${ }^{+}$TNF- $\alpha^{+}$IFN- $\gamma^{-}$) CD4 ${ }^{+}$ T cells at D21 (before boost) and the HI titer at D42 (21 days after boost) in vaccinated subjects. Spearman rank correlation coefficient $r$ and $P$ value are indicated (GraphPad, La Jolla, CA)

\section{DISCUSSION}

All formulations of the H5VLP were well tolerated and no serious adverse event was observed confirming our previous observations. ${ }^{6,14}$ Antibody response, and especially $\mathrm{HI}$ titers, has long been and remains the major criteria driving the development and licensure of egg-based inactivated influenza vaccines. However, $\mathrm{H} 5 \mathrm{~N} 1$-inactivated vaccine has been demonstrated to be a poor $\mathrm{HI}$ titer inducer, requiring adjuvant and prime-boost strategy. ${ }^{3,15}$ All the H5VLP formulations tested in this study elicited an immune response. The alum-adjuvanted groups induced $\mathrm{HI}$ higher antibody titers than previously reported for a plant-produced recombinant $\mathrm{H} 5$ not self-assembling into a VLP ${ }^{16}$, and were similar or slightly higher than what we previously observed for the VLP vaccine ${ }^{6,14}$ and what was observed for an alum-adjuvantedinactivated split virion vaccine. ${ }^{17}$ Antibodies induced by the plantmade H5VLP have previously been demonstrated to be neutralizing with low-to-moderate cross-reactivity. ${ }^{6,14}$ However, alumadjuvanted groups only partially met the CHMP criteria confirming the limited impact of this adjuvant on the humoral response elicited by $\mathrm{H} 5$ vaccines, including H5VLP, in humans. ${ }^{14,18,19}$ By contrast, GLA-adjuvanted groups met all the CHMP criteria even at the lowest dose of $3.75 \mu \mathrm{g} \mathrm{H} 5 \mathrm{VLP}$ in agreement with the significant impact of oil-in-water adjuvants, including MF59 and ASO3, observed with inactivated (split) virion vaccines, ${ }^{20-22}$ or with recombinant $\mathrm{H} 5$ protein. ${ }^{23}$ Although antigen deposition maintaining local antigen concentration was originally seen as the mechanism of action for aluminum salt adjuvants, more recent investigations demonstrated the role of inflammasome activation, release of endogenous danger signals, such as uric acid. On the other hand, the GLA-SE adjuvant, a TLR4 agonist formulated in a stable nano-emulsion of squalene oil-in-water, has been demonstrated to significantly increase the humoral response in animal models and human, as well as to drive Th1 response in vitro and in vivo. ${ }^{24-26}$ Interestingly Ko and co-workers ${ }^{27}$ recently demonstrated that alum adjuvants alone were unable to induce IgG antibodies against split vaccine in CD4KO mice after prime while monophosphoryl lipid A, another TLR4 agonist adjuvant, induced antigen-specific $\lg \mathrm{G} 1$ in wildtype and CD4KO mice. However 


\section{CD4 heterologous response}

$10 \mu \mathrm{g}$ H5VLP+alum

$15 \mu \mathrm{g} \mathrm{H} 5 \mathrm{VLP}+$ alum
$20 \mu \mathrm{g}$ H5VLP+alum

$\square$ Placebo
$3.75 \mu \mathrm{g} \mathrm{H} 5 \mathrm{VLP}+\mathrm{GLA}$

$\$ 7.5 \mu \mathrm{g} \mathrm{H} 5 \mathrm{VLP}+\mathrm{GLA}$

a

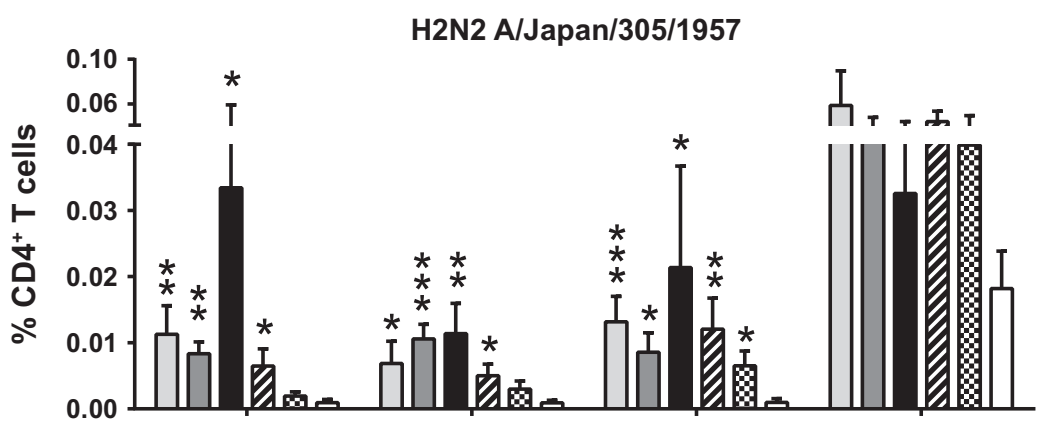

H1N1 A/California/07/2009

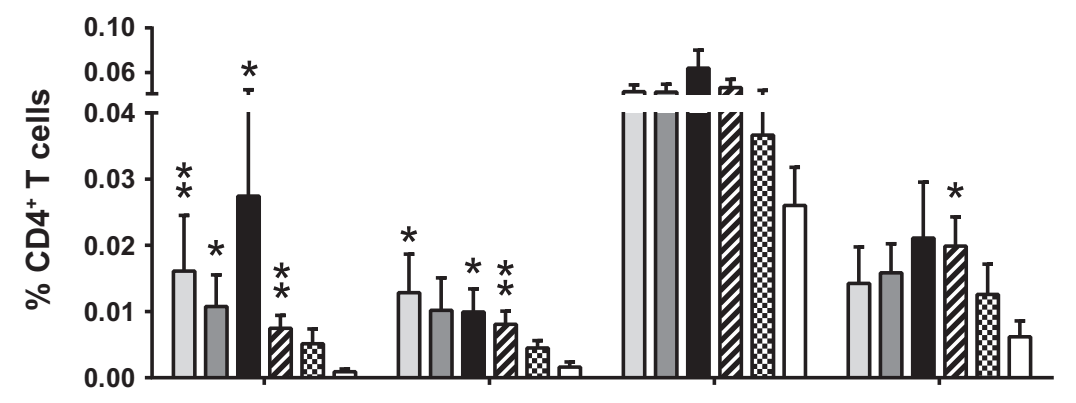

b

D228

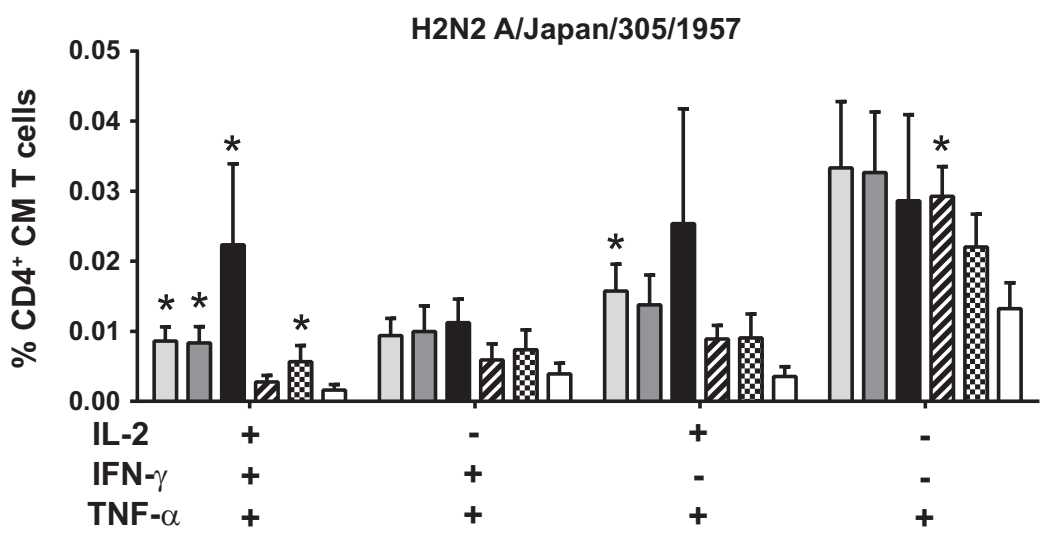

Fig. $4 \mathrm{CD}^{+} \mathrm{T}$ cell heterologous response. PBMCs were stimulated ex vivo with $\mathrm{H} 2$ peptide pool (a lower panel) or $\mathrm{H} 1$ peptide pool (a upper panel). The percentages (mean \pm s.e.m) of H2-specific and H1-specific of the significantly impacted IL-2/IFN- $\gamma /$ TNF- $\alpha$ CD4 ${ }^{+} \mathrm{T}_{\text {cell }}$ functional signatures (detailed at the bottom of the figure) 42 days after prime are represented (a). The memory $\mathrm{CD}^{+} \mathrm{T}_{\text {cell }}$ heterologous response was also measured 228 days after the prime (b). The percentages (mean \pm s.e.m) of the significantly impacted IL-2/IFN- $\gamma / \mathrm{TNF} \alpha \mathrm{CD}^{+}{ }^{+}$central memory $\mathrm{T}$ cell functional signatures (detailed at the bottom of the figure) following ex vivo stimulation with $\mathrm{H} 2$ peptide pool are represented for the five vaccine regimens and Placebo. Asterisks indicate significant differences $\left({ }^{*} P \leq 0.05\right),{ }^{* *} P \leq 0.01$ or $\left.{ }^{* * *} P<0.001\right)$ from Placebo for each individual functional signature (Kruskal-Wallis test, followed by Dunn's multiple comparisons test, GraphPad, La Jolla, CA)

particular mechanisms of action specifically differentiating the different types of adjuvants remain largely unknown. While preformed Abs can be sufficient to provide protection from influenza, $\mathrm{CMI}$ is generally required to effectively clear viral infection and to maintain long-term immunity. Actually, there is a growing consensus that CMI plays a key role in long-term, crossprotective immunity to influenza. ${ }^{10,13,28}$ With the exception of the live-attenuated formulation (LAIV), commercial influenza vaccines are generally very poor inducers of robust anti-viral CMI. $^{29-31}$ Very interestingly, both alum and GLA-adjuvanted H5VLP elicited comparable $T$ cell response although the different doses of antigen would make difficult to compare between the two adjuvants.

We observed a massive (more than one order of magnitude) and sustained increase of $\mathrm{H} 5$-specific IL- $2^{+} / \mathrm{TNF}^{+} \mathrm{a}^{+}\left(\mathrm{IFN}-\gamma^{-}\right) \mathrm{CD}^{+}$ T cells 42 and 228 days after vaccination with both alum and GLA- 
adjuvanted H5VLP vaccine. This confirmed our previous observation of a substantial increase and predominance of this cytokine signature in $\mathrm{H} 5$-specific $\mathrm{CD} 4^{+} \mathrm{T}$ cells 6 months after immunization with an alum-adjuvanted H5VLP vaccine ${ }^{14}$ while revealing that this response actually takes place as soon as 21 days post boost. Influenza-induced IL-2 $2^{+} / \mathrm{TNF}-\mathrm{a}^{+}\left(\mathrm{IFN}-\gamma^{-}\right) \mathrm{CD}^{+} \mathrm{T}$ cells have been described as uncommitted Th1 Thpp preferentially promoted by recent, pandemic epitopes whereas common, multiply-boosted influenza epitope-specific $\mathrm{CD}^{+} \mathrm{T}$ cells expressed IFN- $\gamma$ after influenza infections. ${ }^{32,33}$ Thpp have been proposed to serve as a reservoir of memory $\mathrm{CD}^{+}{ }^{+}$T cells with effector potential. ${ }^{33}$ Our study further revealed that pre-boost Thpp response correlated with post-boost serological response enlightening the potential link between this particular $T$ cells population and the $B$ cell response. The frequency of HA-specific Thpp could therefore appear as an early marker for the subsequent antibody response. The plant-based H5VLP vaccine also induced a significant increase of homologous and cross-reactive TP polyfunctional $\mathrm{CD}^{+} \mathrm{T}$ cells. Polyfunctional $\mathrm{T}$ cells have been associated with better protection in several models, ${ }^{34,35}$ therefore representing an attractive immune cell population to promote after vaccination. The amplitude of cross-reactive $\mathrm{CD}^{+}{ }^{+} \mathrm{T}$ cells observed against $\mathrm{H} 1, \mathrm{H} 2$ and to a lesser extent $\mathrm{H} 7$ was consistent with the sequence homologies of $\mathrm{H} 5$ with those $\mathrm{HA}$ proteins $(74.5,62.5$ and $41.7 \%$ for $\mathrm{H} 2, \mathrm{H} 1$ and $\mathrm{H} 7$, respectively). ${ }^{36}$ As aforementioned, influenza history (infection or vaccination) and its relatively short exposure history may also explain why cross-reactive Thpp T cells responses tend to be higher for $\mathrm{H} 1$ than for the other HA strains. Although heterotypic immunity resulting from influenza infection appeared to be mainly provided by CD8 conserved epitopes of internal influenza proteins like nucleoprotein and $M$ protein, recent data demonstrate that influenza HA molecule also contains class Irestricted and class II-restricted epitopes, and that HA-specific $\mathrm{CD}^{+} \mathrm{T}$ cell response can play significant role in crossprotection. ${ }^{37,38}$

No detectable $\mathrm{CD}^{+}$response was observed at D42. Although induction of major histocompatibility complex-l-restricted $\mathrm{CD}^{+}$ response is best accomplished after endogenous expression of foreign proteins, ${ }^{39}$ dendritic cell-mediated cross-presentation and activation may occurred and has been observed in vitro. ${ }^{40,41}$ However the timing of sample collection as well as the length of peptides used for the ex vivo stimulation may have favored the detection of the $\mathrm{CD}^{+}$response. Ongoing studies are currently investigating the ability of plant-made VLP to stimulated $\mathrm{CD}^{+}$ T cells.

In this study, we further characterized the previously observed long-term CMl elicited by the H5VLP. ${ }^{14}$ We observed that this long-term $\mathrm{CD}^{+} \mathrm{T}$ cell response was characterized by the presence of both $\mathrm{CD} 27^{-}$and $\mathrm{CD} 27^{+}$Ag-specific memory (CD45RA $\left.{ }^{-}\right) \mathrm{T}$ cells. CD27 is a member of the TNF receptor family essential for the survival and accumulation of virus-specific $T$ cells at the site of infection. Mice lacking CD27 are deficient in responding to $T$ cell receptor stimulation and $\mathrm{CD} 27^{-1-}$ transgenic mice displayed a reduced $\mathrm{CD}^{+}$and $\mathrm{CD}^{+}{ }^{+}$cell lung infiltration during influenza infection as compared to wild-type. ${ }^{42,43}$ Lung homing $T$ cells and their proliferation ability have been demonstrated as important correlates of vaccine protection against influenza in mice ${ }^{44}$ and circulating $\mathrm{CD}^{+}$memory cells directed against influenza in human show high expression of $\mathrm{CD} 27^{45}$ with a high proliferative potential and a good ability to provide help to $B$ cells. ${ }^{46}$ The memory response was also altered in $\mathrm{CD} 27^{-/-}$transgenic mice demonstrating the role of CD27 for generation and long-term maintenance of CMI. Interestingly, the long-term heterologous $\mathrm{H} 2$ specific $\mathrm{CD}^{+} \mathrm{T}$ cells response were mainly $\mathrm{CD} 27^{+}$memory cells. Contrasting with the major impact on the humoral immune response, the $C M I$ was marginally influenced by the nature of the adjuvant indicating intrinsic effects of the VLP on T cell response.
In addition to the strong humoral response elicited by the GLAadjuvanted H5VLP vaccine, we also observed a sustained and cross-reactive $\mathrm{CD}^{+} \mathrm{T}$ cell response regardless of the adjuvant nature. While egg-based inactivated influenza vaccine are prone to elicit strong humoral response (with the aforementioned restriction for $\mathrm{H} 5$ ), those vaccine are generally poor inducers of robust CMI as opposed to live-attenuated influenza vaccine (LAIV), which induced substantial T cells response ${ }^{29-31}$ but may run the risk of recombination with circulating strains. Immune protection against influenza infection rely on complex interplay, where $C D 4^{+}$ $T$ cells have been demonstrated to provide significant help to influenza virus-specific Abs, B cell response and $\mathrm{CD}^{+} \mathrm{T}$ cytotoxic response. ${ }^{11,28,47}$ Additionally, Wilkinson and co-workers reported that preexisting influenza-specific $\mathrm{CD}^{+} \mathrm{T}$ cells correlate with disease protection against influenza challenge in humans. ${ }^{48}$ The protection provided by the plant-based VLP vaccine in animal models, including cross-clade protection ${ }^{4,6,8}$ likely lies at least partially in its ability to adequately stimulate both arms of the immune response.

\section{METHODS}

Study design and participants

The phase II trial was a randomized (1:1:1:1:1:1) multicenter, double-blind, placebo-controlled, dose-ranging study (NCT01991561) ${ }^{49}$ conducted in Canada at the McGill University Health Centre (Montreal, QC) and the INC Research Centre (Toronto, ON) between June 2013 and September 2014. The study was carried out in accordance with the Declaration of Helsinki and the principles of Good Clinical Practices and was approved by the site's Ethics Review Board and by the Center for Biologics Evaluation and Research (CBER). Written consent was obtained from all study participants. The randomization was stratified by site and was generated by Veristat (Holliston, MA) using random block permutations obtained with the PLAN procedure from SAS software, version 9.2 (Cary, NC). Allocation was evenly split across the two sites and each site provided a pre-determined sequence of randomization numbers according to the randomization code. The objectives were to evaluate safety, tolerability and immunogenicity of two doses of adjuvanted H5VLP administered intramuscularly (IM). The study included 390 healthy adults of $18-60$ years of age with $\mathrm{BMI} \geq 18$ and $\leq 32$. The other inclusion and exclusion criteria are detailed at Clinicaltrials. gov $^{49}$ and in the detailed protocol (Suppl. Material).

\section{Procedures}

Two hundred-five women and 185 men were allocated into one of the six groups who received two doses (prime-boost) by IM 21 days apart of 10, 15 or $20 \mu \mathrm{g}$ of H5VLP combined with either $500 \mu \mathrm{g}$ Alhydrogel ${ }^{\mathrm{TM}}$ adjuvant (H5VLP + alum), 3.75 or $7.5 \mu \mathrm{g}$ of H5VLP combined with GLA-SE (H5VLP + GLA) or phosphate-buffered saline placebo (65 subjects/group). GLA-SE is a stable oil-in-water emulsion consisting of squalene, glycerol, phosphatidylcholine, polaxamer surfactant and ammonium phosphate buffer at a final concentration of $5 \mu \mathrm{g} \mathrm{GLA} / 2 \%$ SE (w/v) per vaccine dose. Solicited local and general symptoms were recorded 7 days following each vaccine dose. Serum and blood samples were obtained at D0, D21, D42 (21 days after the boost) and D228 after prime for $\mathrm{HI}$ assay and $\mathrm{T}$ cell response against homologous and heterologous strains.

\section{The vaccine}

Production of the H5VLP was based on HA sequence of $A / / n d o n e s i a / 05 /$ 2005 H5N1 influenza strain as previously described. ${ }^{5,8}$

\section{$\mathrm{HI}$ assay}

$\mathrm{HI}$ assay was performed as previously described according to the WHO recommendation. ${ }^{6,50}$ Due to their high pathogenicity, handling live wildtype H5N1 strains require Biosecurity Level 3 facility. The H5VLP was therefore used as surrogate reagent to perform $\mathrm{HI}$ assay. The SCR, SPR and GMFR were defined according to regulatory criteria (CPMP, 1997) $)^{51}$ and were compared to the CHMP criteria i.e., SCR $\geq 40 \%$, SPR $\geq 70 \%$, GMFR $\geq$ 2.5 for healthy adults. 


\section{CMI}

The T cell response was assessed in ten subjects/group at D0, D21, D42 and D228 as previously described. ${ }^{14}$ Briefly, peripheral blood mononucleated cells (PBMC) were stimulated ex vivo with $2.5 \mu \mathrm{g} / \mathrm{ml}$ of peptide pool consisting of 15 mer peptides overlapping by 11 amino acids spanning the complete HA of the homologous A/Indonesia/05/2005 H5N1 (H5) or heterosubtypic A/Japan/305/1957 H2N2 (H2), A/California/07/2009 H1N1 (H1) or A/Hangzhou/1/2013 H7N9 (H7) strains (GenScript, Piscataway, NJ). The markers and the antibodies used for the flow cytometry analysis are detailed in Suppl. Table 2. The data acquisition was performed on BD LSRII flow cytometer (Becton Dickinson, Franklin Lakes, NJ). Approximately $3 \times$ $10^{5}$ viable lymphocytes were acquired for each sample and data were analyzed using FlowJo ${ }^{\mathrm{TM}}$ v9.7 (Tree Star, OR), Pestle v1.7 and SPICE v5.2 (Mario Roederer, Vaccine Research Centre, National Institutes of Health, USA, available at http://exon.niaid.nih.gov/spice) softwares. The gating strategy is detailed in Suppl. Figure 2. The total cell viability was always $>85 \%$. SPICE-based functional analysis was performed on backgroundsubtracted values from non-stimulated PBMC.

\section{Statistical analysis}

The sample size of 65 subjects per group was based on previously published results ${ }^{6,14}$ and on the probability of meeting CHMP criteria. Analysis of variance (ANOVA) and Fisher's exact tests were respectively used for treatment comparisons of continuous variables and proportions of the demographics and baseline data (SAS software, version 9.2). Fisher's exact test was also used to compare the occurrence of solicited symptoms between vaccinated subjects and Placebo (Prism ${ }^{\mathrm{TM}}$ Software v6.0, GraphPad, La Jolla, CA). Differences in $\mathrm{CD}^{+} \mathrm{T}$ cell response over the time in the vaccinated groups and Placebo were analyzed by two-way ANOVA followed by a Dunnett's multiple comparison post hoc analysis. The increase of frequencies between D0 and D42 for each $\mathrm{CD}^{+}$subpopulations characterized by their cytokine signature was addressed by a Wilcoxon matched-pairs signed rank test (Prism ${ }^{\mathrm{TM}}$ Software v6.0, GraphPad, La Jolla, CA). A Kruskal-Wallis test, followed by Dunn's multiple comparison post hoc analysis were conducted independently for each adjuvant type to identify the significant differences between vaccinated groups and Placebo at different time-points (Prism ${ }^{\text {TM }}$ Software v6.0, GraphPad, La Jolla, CA). Correlations between CMI and humoral responses were addressed by the Spearman rank correlation test (Prism ${ }^{\mathrm{TM}}$ Software v6.0, GraphPad, La Jolla, CA). Differences with a $P$ value $<0.05$ were considered significant.

\section{Data availability}

Clinical data that support the findings of this study are available from Medicago Inc. but restrictions apply to the availability of these data. Data are, however, available from the authors upon reasonable request and with permission of Medicago Inc. To protect the privacy of patients and individuals involved in our studies, Medicago Inc. does not publically disclose patient-level data.

\section{ACKNOWLEDGEMENTS}

The authors are indebted to participating study volunteers. We are grateful to the sponsor's project staff for their support and contributions throughout the study particularly to Sebastien Soucy and Isabelle-A.Vandandaigue for the management of the clinical study as well as Diane Buissière and Michelle Dargis for processing the $\mathrm{HI}$ assays. Particular thanks to Marie-Pier Gervais and Kathya Daigle for their valuable support in the data management. Finally, we recognized the great contribution and effort of the Medicago's employees who developed and produced the quadrivalent plant-made VLP for this clinical study. This study was sponsored by Medicago Inc. B.J. W and S.P. were supported by the Canadian Institutes of Health Research (UI201303).

\section{AUTHOR CONTRIBUTIONS}

N.L., S.T., J.M. and B.J.W. designed the clinical trial; J.M. provided material; J-F.P. and B. Y-D. managed the cell-mediated immunity assays; S.P., É.A., J-F.P. and B.Y-D. analyzed the data; S.P. and É.A. prepared the manuscript; N.L., S.T., J.tM. and B.J.W. provided feedback on the manuscript.

\section{ADDITIONAL INFORMATION}

Supplementary information accompanies the paper on the npj Vaccines website (https://doi.org/10.1038/s41541-017-0043-3).

Competing interests: B.J.W. has been a principal investigator of vaccine trials for several manufacturers, including Medicago Inc., for which his institution obtained research contracts. Since 2010, B.J.W. served as Medical Officer for Medicago Inc. In addition, B.J.W. has held and continued to hold peer-reviewed support from Canadian Institutes of Health Research and other sources for collaborative, basic science work with Medicago Inc. B.J.W. has received honoraria from several vaccine manufacturers for participation on Scientific Advisory Boards (including Medicago Inc). N.L., S.T., S.P. and É.A. are employees of Medicago Inc. J.M. is a full-time employee and shareholder of Immune Design. The remaining authors declare no competing financial interests.

Publisher's note: Springer Nature remains neutral with regard to jurisdictional claims in published maps and institutional affiliations.

\section{REFERENCES}

1. WHO. Cumulative number of confirmed human cases of avian influenza $A(H 5 N 1)$ reported to WHO http://www.who.int/influenza/human_animal_interface/ H5N1_cumulative_table_archives/en/ (2016).

2. Yang, Y. et al. The transmissibility and control of pandemic influenza A (H1N1) virus. Science 326, 729-733 (2009).

3. Baz, M., Luke, C. J., Cheng, X., Jin, H. \& Subbarao, K. H5N1 vaccines in humans. Virus Res., https://doi.org/10.1016/j.virusres.2013.05.006 (2013).

4. D'Aoust, M. A. et al. Influenza virus-like particles produced by transient expression in Nicotiana benthamiana induce a protective immune response against a lethal viral challenge in mice. Plant Biotechnol. J. 6, 930-940 (2008).

5. D'Aoust, M. A. et al. The production of hemagglutinin-based virus-like particles in plants: a rapid, efficient and safe response to pandemic influenza. Plant Biotechnol. J. 8, 607-619 (2010).

6. Landry, N. et al. Preclinical and clinical development of plant-made virus-like particle vaccine against avian H5N1 influenza. PLoS. One 5, e15559 (2010).

7. Ward, B. J. et al. Human antibody response to N-glycans present on plant-made influenza virus-like particle (VLP) vaccines. Vaccine 32, 6098-6106 (2014).

8. Pillet, S. et al. Plant-derived H7 VLP vaccine elicits protective immune response against H7N9 influenza virus in mice and ferrets. Vaccine 33, 6282-6289 (2015).

9. Sridhar, S. et al. Cellular immune correlates of protection against symptomatic pandemic influenza. Nat. Med. 19, 1305-1312 (2013).

10. Schotsaert, M., Saelens, X. \& Leroux-Roels, G. Influenza vaccines: T-cell responses deserve more attention. Expert. Rev. Vaccin. 11, 949-962 (2012).

11. Altenburg, A. F., Rimmelzwaan, G. F. \& de Vries, R. D. Virus-specific T cells as correlate of (cross-)protective immunity against influenza. Vaccine 33, 500-506 (2015).

12. Furuya, Y. et al. Cytotoxic T cells are the predominant players providing crossprotective immunity induced by \{gamma\}-irradiated influenza A viruses. J. Virol. 84, 4212-4221 (2010).

13. Zens, K. D. \& Farber, D. L. Memory CD4 T cells in influenza. Curr. Top. Microbiol. Immunol. 386, 399-421 (2015).

14. Landry, N. et al. Influenza virus-like particle vaccines made in Nicotiana benthamiana elicit durable, poly-functional and cross-reactive $T$ cell responses to influenza HA antigens. Clin. Immunol. 154, 164-177, https://doi.org/10.1016/j. clim.2014.08.003 (2014).

15. Leroux-Roels, I. \& Leroux-Roels, G. Current status and progress of prepandemic and pandemic influenza vaccine development. Expert. Rev. Vaccin. 8, 401-423 (2009).

16. Chichester, J. A. et al. Safety and immunogenicity of a plant-produced recombinant hemagglutinin-based influenza vaccine (HAl-05) derived from A/Indonesia/05/2005 (H5N1) influenza virus: a phase 1 randomized, double-blind, placebocontrolled, dose-escalation study in healthy adults. Viruses 4, 3227-3244 (2012).

17. Bresson, J. L. et al. Safety and immunogenicity of an inactivated split-virion influenza A/Vietnam/1194/2004 (H5N1) vaccine: phase I randomised trial. Lancet 367, 1657-1664 (2006).

18. Young, B. E., Sadarangani, S. P. \& Leo, Y. S. The avian influenza vaccine Emerflu. Why did it fail? Expert. Rev. Vaccin. 14, 1125-1134 (2015).

19. Bernstein, D. I. et al. Effects of adjuvants on the safety and immunogenicity of an avian influenza H5N1 vaccine in adults. J. Infect. Dis. 197, 667-675 (2008).

20. Leroux-Roels, I. et al. Antigen sparing and cross-reactive immunity with an adjuvanted $\mathrm{rH} 5 \mathrm{~N} 1$ prototype pandemic influenza vaccine: a randomised controlled trial. Lancet 370, 580-589 (2007).

21. Moris, P. et al. H5N1 influenza vaccine formulated with AS03 A induces strong cross-reactive and polyfunctional CD4 T-cell responses. J. Clin. Immunol. 31, 443-454 (2011). 
22. Keitel, W. et al. Dose ranging of adjuvant and antigen in a cell culture H5N1 influenza vaccine: safety and immunogenicity of a phase $1 / 2$ clinical trial. Vaccine 28, 840-848 (2010)

23. Treanor, J. J. et al. Evaluation of safety and immunogenicity of recombinan influenza hemagglutinin ( $\mathrm{H} 5 /$ Indonesia/05/2005) formulated with and without a stable oil-in-water emulsion containing glucopyranosyl-lipid A (SE + GLA) adjuvant. Vaccine 31, 5760-5765 (2013).

24. Baldwin, S. L. et al. Enhanced humoral and Type 1 cellular immune responses with Fluzone adjuvanted with a synthetic TLR4 agonist formulated in an emulsion. Vaccine 27, 5956-5963 (2009).

25. Behzad, $H$. et al. GLA-SE, a synthetic toll-like receptor 4 agonist, enhances T-cell responses to influenza vaccine in older adults. J. Infect. Dis. 205, 466-473 (2012).

26. Coler, R. N. et al. Development and characterization of synthetic glucopyranosy lipid adjuvant system as a vaccine adjuvant. PLoS. One 6, e16333 (2011).

27. Ko, E. J. et al. Roles of aluminum hydroxide and monophosphoryl lipid A adjuvants in overcoming $\mathrm{CD} 4+\mathrm{T}$ cell deficiency to induce isotype-switched lgG antibody responses and protection by T-dependent influenza vaccine. J. Immunol. 198, 279-291 (2017).

28. McKinstry, K. K., Dutton, R. W., Swain, S. L. \& Strutt, T. M. Memory CD4 T cellmediated immunity against influenza $A$ virus: more than a little helpful. Arch Immunol. Ther. Exp. (Warsz.). 61, 341-353 (2013).

29. Hoft, D. F. et al. Live and inactivated influenza vaccines induce similar humoral responses, but only live vaccines induce diverse T-cell responses in young children. J. Infect. Dis. 204, 845-853 (2011).

30. Subbramanian, R. A., Basha, S., Shata, M. T., Brady, R. C. \& Bernstein, D. I. Pandemic and seasonal H1N1 influenza hemagglutinin-specific $T$ cell responses elicited by seasonal influenza vaccination. Vaccine 28, 8258-8267 (2010).

31. Mohn, K. G. et al. Longevity of B-cell and T-cell responses after live attenuated influenza vaccination in children. J. Infect. Dis. 211, 1541-1549 (2015).

32. Deng, N., Weaver, J. M. \& Mosmann, T. R. Cytokine diversity in the Th1-dominated human anti-influenza response caused by variable cytokine expression by Th1 cells, and a minor population of uncommitted IL-2 + IFNgamma- Thpp cells. PLoS. One. 9, e95986 (2014)

33. Weaver, J. M. et al. Increase in IFNgamma(-)IL-2(+) cells in recent human CD4 T cell responses to 2009 pandemic H1N1 influenza. PLoS. One 8, e57275 (2013).

34. Makedonas, G. \& Betts, M. R. Polyfunctional analysis of human t cell responses: importance in vaccine immunogenicity and natural infection. Springe. Semin. Immunopathol. 28, 209-219 (2006).

35. Seder, R. A., Darrah, P. A. \& Roederer, M. T-cell quality in memory and protection: implications for vaccine design. Nat. Rev. Immunol. 8, 247-258 (2008).

36. Righetto, I., Milani, A., Cattoli, G. \& Filippini, F. Comparative structural analysis of haemagglutinin proteins from type $A$ influenza viruses: conserved and variable features. BMC Bioinform. 15, 363 (2014).

37. Duvvuri, V. R. et al. Highly conserved cross-reactive CD4+ T-cell HA-epitopes of seasonal and the 2009 pandemic influenza viruses. Influ. Other Respir. Virus 4 249-258 (2010)

38. Lee, L. Y. et al. Memory $T$ cells established by seasonal human influenza $A$ infection cross-react with avian influenza $A(\mathrm{H} 5 \mathrm{~N} 1)$ in healthy individuals. J. Clin. Invest. 118, 3478-3490 (2008)
39. Koup, R. A. \& Douek, D. C. Vaccine design for CD8 T lymphocyte responses. Cold Spring Harb. Perspect. Med. 1, a007252 (2011).

40. Machy, P., Serre, K. \& Leserman, L. Class I-restricted presentation of exogenous antigen acquired by Fcgamma receptor-mediated endocytosis is regulated in dendritic cells. Eur. J. Immunol. 30, 848-857 (2000).

41. Song, $\mathrm{H}$. et al. In vitro stimulation of human influenza-specific CD8+ T cells by dendritic cells pulsed with an influenza virus-like particle (VLP) vaccine. Vaccine 28, 5524-5532 (2010).

42. Hendriks, J. et al. CD27 is required for generation and long-term maintenance of T cell immunity. Nat. Immunol. 1, 433-440 (2000).

43. Borst, J., Hendriks, J. \& Xiao, Y. CD27 and CD70 in T cell and B cell activation. Curr. Opin. Immunol. 17, 275-281 (2005).

44. Lin, J., Somanathan, S., Roy, S., Calcedo, R. \& Wilson, J. M. Lung homing CTLs and their proliferation ability are important correlates of vaccine protection against influenza. Vaccine 28, 5669-5675 (2010).

45. Lucas, M. et al. Ex vivo phenotype and frequency of influenza virus-specific CD4 memory T cells. J. Virol. 78, 7284-7287 (2004)

46. Tortorella, C. et al. Expression of CD45RB and CD27 identifies subsets of CD4+ memory $\mathrm{T}$ cells with different capacities to induce $\mathrm{B}$ cell differentiation. J. Immunol. 155, 149-162 (1995).

47. Teijaro, J. R. et al. Cutting edge: tissue-retentive lung memory CD4 T cells mediate optimal protection to respiratory virus infection. J. Immunol. 187, 5510-5514 (2011).

48. Wilkinson, T. M. et al. Preexisting influenza-specific CD4+ T cells correlate with disease protection against influenza challenge in humans. Nat. Med. 18, 274-280 (2012)

49. Clinicaltrials.gov. NCT01991561 https://clinicaltrials.gov/ct2/show/NCT01991561 (2013).

50. WHO. Manual on animal influenza diagnosis and surveillance. http://www.wpro who.int/NR/rdonlyres/EFD2B9A7-2265-4AD0-BC98-97937B4FA83C/0/manualonanimalaidiagnosisandsurveillance.pdf (2002).

51. CPMP, C. f. P. M. P. Note for Guidance on Harmonisation of Requirements for Influenza Vaccines CPMP/BWP/214/96 (The European Agency for the Evaluation of Medicinal Products [EMEA], London, 1997).

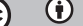

pen Access This article is licensed under a Creative Common Attribution 4.0 International License, which permits use, sharing, adaptation, distribution and reproduction in any medium or format, as long as you give appropriate credit to the original author(s) and the source, provide a link to the Creative Commons license, and indicate if changes were made. The images or other third party material in this article are included in the article's Creative Commons license, unless indicated otherwise in a credit line to the material. If material is not included in the article's Creative Commons license and your intended use is not permitted by statutory regulation or exceeds the permitted use, you will need to obtain permission directly from the copyright holder. To view a copy of this license, visit http://creativecommons. org/licenses/by/4.0/.

(c) The Author(s) 2018 